\title{
Virtual and Augmented Reality for Developing Emotional Intelligence Skills
}

\author{
https://doi.org/10.3991/ijes.v9i3.23939 \\ Chara Papoutsi ${ }^{1,2(\bowtie)}$, Athanasios Drigas $^{1}$, Charalabos Skianis ${ }^{2}$ \\ ${ }^{1}$ Institute of Informatics and Telecommunications, \\ N.C.S.R. 'Demokritos', Athens, Greece \\ ${ }^{2}$ University of the Aegean, Samos, Greece \\ papoutsi.xara@yahoo.com
}

\begin{abstract}
The development and the cultivation of emotional intelligence and of the skills it can offer to the individual are the main elements and pursuits of contemporary research. The enhancement of self-control, the reinforcement of self-criticism and self-awareness and the cultivation of the constant self-development are the most central objectives of all the people and of the scientists since they are the cornerstone for euphoria. The aim of the present study is the review and the critical reproduction of information and conclusions that have been extracted from the international bibliography regarding the issue in question. More specifically, there will be an effort to evaluate and present the significance of the activities of virtual reality and of augmented reality that contribute to the development of emotional intelligence skills. Along the same lines, there will be an important review of the articles that refer to the exploitation of such digital tools, to achieve the same results for the people suffering from autism as well. Besides, the care for all the members of the society with no exceptions, and certainly of those members that suffer from mental retardation, should be of upmost importance. The present article focuses on the role that those tools play for the amplification of the skills in the sphere of emotional intelligence not only as far as the duration of the research is concerned.
\end{abstract}

Keywords-emotional intelligence, virtual reality, augmented reality, emotional enhancement, autism

\section{Introduction}

One of the main objectives of the societies nowadays but also of the agents and the institutions is the development and the cultivation of the main emotional and social skills in children and in people of any age group. Those skills-capabilities allow the smooth integration in the community and the parallel promotion of a spirit that is characterized by cooperation and collectivity, which in the end allows the meaningful and effective socialization of the persons. To achieve the goal in question, there has been a suggestion in the international bibliography and research of the significance of instilling and developing the main skills of the citizens that are related to emotional intelligence. 
Emotional intelligence is a prominent concept that for the last decades has been at the forefront of scientific research, of workplaces, of educational field and of other areas. It is the ability to recognize, to express, and to understand the emotions of self and the others, to manage and to control the emotions of self and the others, to show empathy until the growth in higher levels that of self-actualization and self-transcendence where people reach their full potential and inspire others for their self-fulfillment $[1,2]$. Emotional intelligence can be trained through programs, strategies and in recent years a serious effort has been made to cultivate emotional skills through software, mobile applications, serious games, virtual and augmented reality following the rapid advancement of technology [3-6].

Children and adults need to be able to showcase stable aspects of emotional intelligence and to cultivate the social part of themselves to the greatest degree possible for better collaboration and cooperation and social interaction [7]. The sociability and the high rates of team effort and collectivity certainly require an equivalent appearance of particular and basic characteristics that refer to that very need of highlighting psychological, emotional, and social skills. At this point, it is of upmost importance in the various technological means that there are elements related to emotion recognition, emotional self-awareness, self-control, self-management, self-confidence, self-criticism and to a more general tendency of the individuals to improve themselves. Besides, in virtual and augmented reality the development of characteristics and of aspects that amplify the personality and that act in a beneficial way in the behavior of the people will be driving forces for their progression [8].

Therefore, the goal in question can be promoted - if not achieved fully and surelythrough the exploitation of virtual and augmented reality. It is in fact a method of presenting the environment and the characteristics that compose it in such a way that the creation is credible and relates to reality as much as it possible. The presentation of those elements can be either direct or indirect and it refers to either the synchrony or the diachrony of a theme, providing a plethora of activities to the maker himself or to the user [9]. The people who take part in those kinds of activities-programs manage to meet a virtual way of presenting situations and natural elements and, at the same time, they have the illusion that what is happening in the virtual reality corresponds to reality. As a result, they can transmit a lot of the virtues-relations and behaviors that are showcased during their participation to the virtual life to the real world as well [10].

It is important to clarify that virtual reality is founded upon the use of various digital and technological methodological tools and, for that reason, it has been used to a great extent and it has met a lot of fame. The companies themselves that include and deal with digital data have made clear a significant degree of corresponding to the real time and space. The media created and designed of that very activity are part of a vast gamma and, thus, they offer opportunities but also more possibilities to appear effective.

At this point of the research, there must be before-hand a clarification that will shed light on the case and deter any miscommunication. However, virtual reality and augmented reality are under no circumstance the names of the same concept and they should not be treated as such.

On one hand, virtual reality is the presentation of exclusively virtual and contrived objects and situations and the parallel presentation of a purely imaginary life 
that resembles reality without, of course, being the reality to trigger emotional reactions [11]. Solely technological media and other corresponding digital tools are used, which help, in the end, in the appearance and reproduction of new-always imaginary and contrived - situations and objects that can make an appearance in the everyday life of people. In other words, virtual reality refers exclusively to elements, data and materials that represent reality and that reproduce the latter to a great extent, while not having any contact with it through the former [12].

On the other side of the spectrum, one can find augmented reality. The etymology of the term is a testament to the intense and more extremely, to an extent, depiction of reality and of natural-everyday conditions. That kind of virtuality is based on an effort for the existence of real data that correspond to reality but in combination with additional elements that do not appear in reality and in everyday life [13]. In fact, it is a method of enriching reality in a parallel way, giving to the user the opportunity to experience something s/he cannot achieve or see based on the real and natural data [14]. It offers the appropriate circumstances for the depiction of new elements that have as their basis-foundation reality and not plausibility [15].

Surely, the issue under scrutiny has already been analyzed and assessed by many scientists and researchers who have managed to verify their thesis and offer a multitude of articles. As expected, the bibliography is quite extensive and it is an important source of information and of data that are related to the very ways that augmented reality, as well as virtual reality, can both operate in a positive way and for a future study of the issue.

Briefly, the main difference of the two concepts is related to the way that the picture and the reality are depicted in each one of them [16]. The first one (VR-Virtual Reality) refers to the complete reconstruction of reality by placing solely digital elements, while the second one (AR-Augmented Reality) refers to the proper reconstruction of digital elements so that they fit with real situations and conditions. It is a knowledge that was developed and evaluated after a thorough study by some scientists, who in 2017 published an article that delt with the differences that can be traced between virtual and augmented reality [15].

As far as the differences between those methodological and digital tools are concerned, the research group of Bonetti F. conducted an important research and reached the same conclusions. The team in question managed to show the main characteristics that differentiate those two practices through a systematic review of certain basic elements that were mentioned in a plethora of articles [12].

Furthermore, at this point we could include another important and effective, for the bibliography but also for the theme, article that refers to that very differentiation and that was conducted as a research and published as an article in 2020. Boardman et al., (2020) studied aspects regarding fashion and entrepreneurship, and not social characteristics and emotional skills as much like in the present study, thus showing the spread and usefulness of virtual and augmented reality in other areas as well [17].

The issue under scrutiny refers to the cultivation of skills regarding emotional intelligence. The goal is the acquisition by the individual of a plethora of emotional and other psychological phenomena that will allow a parallel development of his/her emotional intelligence and sociability. 


\section{Methods}

\subsection{Search procedure/analysis}

During the very first months of the year 2021 and, more specifically, during the month February, a work was conducted; the gathering of information through the review of the bibliography regarding the emotional intelligence on virtual and on augmented reality. Through the visitation of digital libraries and of more general sources, that include scientific articles and studies, a better understanding of the issue under scrutiny was achieved. In any case, to achieve the best possible study of the issue of amplifying emotional skills, the review regarded articles that dated only from 2010 to 2020 . That way, there will be a more organized and well-rounded understanding of the issue at hand and at the same time there will be an acquisition of more contemporary information.

The electronical sources utilized for the realization of the present study are the main websites and online media that allow the study of the issue. More specifically, Medline (PubMed version), Science Direct and ACM Digital Library were used, which offer a more general access to scientific resources without limitations (Table 1). All the articles are mostly based on research or reviews of the bibliography (to a lesser extent) regarding the significance and the role played by virtual and augmented reality in various situations and much more regarding the emotional level.

Therefore, the keywords that were used were mainly the following: "virtual reality", "augmented reality", "emotional intelligence", "autism" and "technique-technology". We should not omit the fact that the articles that referred to the importance of those technological methods for the fight against autism were quite important and were used for the present study.

Table 1. Total number of papers identified from each database, identified following screening, selected as meeting inclusion criteria and quality coded over 9

\begin{tabular}{|l|c|c|c|c|}
\hline Database & $\begin{array}{c}\text { Number of } \\
\text { Papers Found } \\
\text { by Database } \\
\text { Search }\end{array}$ & $\begin{array}{c}\text { Number of Papers } \\
\text { Identified Following } \\
\text { Screening for } \\
\text { Games Terms }\end{array}$ & $\begin{array}{c}\text { Number of Papres } \\
\text { Selected as } \\
\text { Meeting Inclusion } \\
\text { Criteria }\end{array}$ & $\begin{array}{c}\text { Number } \\
\text { of Papers } \\
\text { Rated } \\
\text { Over } 9\end{array}$ \\
\hline Medline & 251 & 51 & 28 & 4 \\
\hline Science Direct & 16,442 & 7,389 & 40 & 8 \\
\hline $\begin{array}{l}\text { ACM Digital } \\
\text { Library }\end{array}$ & 354,547 & 101,368 & 42 & 7 \\
\hline
\end{tabular}

\subsection{Inclusion procedure}

A cornerstone for the conduction of the present study was the study of articles referring solely to the usage of virtual and augmented reality with the keywords mentioned above. As a result, it is quite evident that there was a rejection and an exclusion of studies that referred generally to the importance of technology and to the usage of digital media as a whole. Particularly, to achieve a more informed and organized study, there was an effort to include only articles and studies that are based on research (primary) and on review of the bibliography. 


\subsection{Data extraction and quality quantification}

The selection of the articles was done through a thorough study of the theme but also of the quality of information that each article offered. The system Yusoff made that possible through the evaluation of the texts. The system allows the assessment of texts and scientific articles in such a way that basic rules ensuring objectivity are implemented. At the same time, what was also important was the existence of the proper images and the way the articles themselves evaluated their review, since, by extension, they allowed the appropriate selection of the latter by studying not only the way the research was conducted but also the assessment realized regarding their sources [18].

The scale of quality refers to and includes the elements of fully corresponding to the issue at hand as well. In other words, many articles did not have an immediate relation with the theme, and they presented in a superficial way the events and the information, simply describing a situation without having indulged appropriately. For that reason, the scale of evaluation by Yusoff was chosen and used. He assessed texts with no relevance ( 0 in the scale), with medium relevance (1 in the scale) and with a high degree of relevance ( 2 in the scale). Therefore, there was a better connection and coherence in the way of evaluating the sources used [18].

\section{Results}

There was a quite extended research regarding to the importance and to the characteristics of virtual and augmented reality, which gave prominence to a plethora of information. It is of upmost importance to highlight that the present article has followed in a productive way the structure of an article that was published in 2020 by Pranav Parekh [7]. The article is founded upon a systematic review of the bibliography and of the studies that have been done regarding the theme in question. The article includes data and research that refer to the use of virtual and augmented reality in the pharmaceutical discipline and, by extension, in medicine, in retail and in games-entertainment. On the contrary, the present study will focus on the exploitation of media of the reality through technology for the cultivation of emotional intelligence.

To achieve a better organization and structure of the information, there will be a study of two main categories. Virtual reality will be analyzed separately from augmented reality in terms of the development of emotional skills and the results through their use. All the scientists and scientific teams have chosen to distinguish those two concepts and to study team in a different and more systematic context

\subsection{Virtual reality}

Sofia Myrislaki and Fotini Paraskeva have published a relevant article. In the article there is an extended presentation of a research investigating the effects of leaders' emotional intelligence and transformational leadership on virtual team effectiveness that was conducted with 500 people. Those people took part in a massively multiplayer online game (MMOGs) that included virtual reality and that way they were led to specific conclusions. It was understood that the participation in those kinds of activities 
amplified to a great extent the unity of the members and helped them develop their feelings and achieve the acquisition of a higher degree of confidence and satisfaction through the transformational leadership that mediates the relationship between leaders' emotional intelligence and team effectiveness. The participants were split into groups and each member of the team had a different responsibility and role to play in the process [19]. Furthermore, the researchers analyzed and assessed through a schema the practical contribution of developing the leader's emotional intelligence for the cultivation of collectivity and of a higher degree of the members-participants' efficiency and their emotional empowerment [19]. Emotional intelligence is a necessary component and plays a key role in organizational effectiveness and excellence having positive correlations between leaders, employees, and other working variables [20,21].

Additionally, another article published in 2019 was fundamental for the writing of the present study. Claudia Carissoli and Daniela Villani conducted a research in which 121 students at high school took part in EmotivaMente, a program which aims to promote emotional intelligence in early adolescents using guided and structured videogames as tools for experiential learning. More specifically, through the research, the scientists reached the conclusion that a great number of the students-adolescents reported an improvement in the evaluation and expression of emotions in relation to the self and others and an increase in emotion regulation strategies after the occupation with the videogames. The children had the opportunity to comprehend themselves even volitionally the emotions born after the experience and, with that way, they could acquire self-criticism and to improve themselves [22]. Moreover, a number of videogames helped them to promote empathy, to listen to different points of view for better self and social awareness and constructive collaborations and interactions.

At the same time, one year later, in 2018, Ip H. H. S. et al. (2018) published an article after a primary research that referred to children with autistic disorders and other similar problems. The disorder that they are called to be faced with do not give them the opportunity to cultivate their emotional and social capabilities and to acclimatize-be integrated in the various social groups that are formed in their environment. For that reason, the researchers made efforts to progress and to amplify, to the greatest degree possible, the emotional and social capabilities-abilities of the children that are faced with that disorder. The 94 children had to occupy themselves with six educational scenarios that were designed following the method of virtual reality focuses on emotion control, relaxation strategies, simulation on various social situations, and consolidation-generalization. The research showed that children improved emotion expression, emotion regulation and social interaction substantially [23].

Another systematic review was done by Mesa-Greza et al., in 2018. There was an evaluation, through some especially important for science articles, of the value of virtual reality for the sociability, the cooperation, and the collectivity of the persons to amplify the relations between the members of the team. On the other hand, there was also an assessment of the technological support for the children dealing with those kinds of mental difficulties to be able to externalize their feelings. Besides, the objective of the study of those researches in this article is the approach of virtual reality for the development of emotional intelligence [24].

A virtual environment-based therapy for the strengthening of social skills, emotion, and attention of children with autistic spectrum disorders was proposed by Manju et al. 
in 2018. Children interact with the virtual environment through a range of activities. The virtual environment has three levels which are related to attention training, social and emotional skills and decision making. The entire system was encircled with Cameras, Tracking System, Gesture recording system, and Audio-Visual Recording System. Rehabilitation therapy with the help of the virtual environment had positive results with the repetition and helped to address attention deficit, social interaction, and emotional value [25].

Three other articles that are related to the importance of virtual reality in the fight against problems of mental retardation should me mentioned. The first article that will be presented was published in 2017. It is a collective study-research that was conducted by Yang and his associates. They carried out a research with 17 young adults with high-functioning ASD. The young adults received Virtual Reality Social Cognition Training which was designed to enhance socio-emotional processing and socio-cognitive reasoning skills in children and young adults with ASD. Through a virtual role-play intervention program there were improvements in emotion recognition and theory of mind [26].

Furthermore, Didehbani and her associates published an article during the year 2016 where they talked about the very significance of the act of adopting programs and methods of virtual reality for the improvement of social and emotional skills of the children that face problems and disorders which are included in the sphere of autism. The study investigated the impact of a Virtual Reality Social Cognition Training (VR-SCT) to enhance social skills in 30 children with ASD. Results showed that VR-SCT contributed to the improvement of emotion recognition, social attribution, and executive function of analogical reasoning [27].

Lorenzo et al. (2016) proposed an Immersive Virtual Reality System (IVRS) for the training, the development, and the improvement of the deficits that students with ASD experience in emotional skills. The survey was conducted in forty students from primary schools, between 7 and 12 years old who were diagnosed with ASD. Ten social stories based on real situations were introduced to the user who interacted with the IVRS and had the support from the evaluator. Through the social stories and a computer vision system which recorded the students' responses and emotional states students were able to practice their emotional responses and were trained in appropriate emotional behaviors. The results showed that with the visual and interactive learning there was a noteworthy improvement in children's emotional and social skills [28].

In 2015, Diemer et al., published another article. The team in question studied extensively the role that technology and, more particularly, that virtual reality is called to play in the development of emotional intelligence. They concluded that the role of the method-technology under scrutiny is to allow the participants-users to externalize more easily their emotions. Through their occupation with the various games and activities offered by virtual reality, the individual can reveal what $\mathrm{s} / \mathrm{he}$ is feeling and present himself/herself to the community. In other words, virtual reality is in fact the medium so that the individual can cultivate all kinds of emotions and parallelly externalize said emotion [11]. However, in that case, the researchers studied the way that the users and the participants reacted on many occasions. Their reactions and virtual reality could help to a great extent eliminate main spiritual and mental disorders. 
Furthermore, Bekele et al. (2013) published an article in 2013. In this article there is an analysis of a research conducted to study the emotion recognition and response to facial expressions between adolescents who suffer from autism and adolescents who do not suffer from any kind of mental problem. The research concluded that both groups had the opportunity to express their emotions through the virtual reality but there were differences in the way adolescents with ASD process and recognize emotional faces compared to their typically development peers. It was observed that there was a more intense relationship with the expected effect of that digital method with people with autism, verifying the hypothesis of its effectiveness on them [29]. A multimodal virtual reality-based social interaction platform for children with ASD was also used for emotion recognition in a social context demonstrating the viability and functionality of the VR system [30].

It is also worth mentioning an article which, although it emerged from the database and it was not included in the 19 final articles that came out of the last selection, deals with the development of emotional intelligence through virtual reality in a different industry. The article is referred on the integration of emotional intelligence training into military practicing and related programs using virtual reality and more specifically emotionally expressive virtual characters in combination with various strategies. It is argued that emotional intelligence needs to be cultivated because it is necessary in real military operations so that operational teams can manage and use their emotions properly, make constructive decisions, and interact more effectively. The article describes how this approach could be implemented and how emotion recognition and regulation skills would be exercised and assessed [31].

\subsection{Augmented reality}

In a recent study the benefits and the prospects arising from the integration of augmented reality in the educational process were examined, and more specifically in the language and literary field of primary education and simultaneously, it was presented the effectiveness of student's literacy with the help of AR [32]. The research - 68 students from experimental classes (EC) and 67 students from control classes (CC) - showed that using and reading augmented reality books can open new artistic horizons, activate students' imagination, develop emotional intelligence and creative thinking, increase children's motivation and interest, promote social interaction, and give aesthetic pleasure. The activities that can take place and the interaction between students, but also the active imaginary dialogue with the heroes of the books can emerge a plethora of emotions and give many opportunities for the cultivation of emotional skills.

Another study was performed on 38 children aged 9 to 11 years old who participated in a multiplayer mobile augmented reality (MAR) game in a geolocation scenario named EmoFindAR. Through this game children were trained in recognizing emotions and took part in action that are related to the perception, assimilation, understanding and regulation of emotions. Simultaneously, because it is a multiplayer environment, it cultivates the communication and the collaboration between players even though the said game supports and examines two different game modes, the competitive and the collaborative one. The results showed that the augmented reality game triggered positive emotions in both modes, increased the degree of involvement, and acted with a positive sign on emotional affection, social interaction, and interest [33]. 
A game of augmented reality, called "Pokemon GO", appears to have given a significant boost to emotional enrichment. The game is particularly known and favored, and it is one of the most popular games of the last five years. Its main users are adolescents and children who are interested more in technological and electronical games [34].

The research took place in Spain and more specifically in Andalucia. A number of 190 adolescents from two different summer schools took part. The research, which lasted about two months, focused on behavior change and whether the interaction with the game played a role in it. The aim was to examine the effect of the "Pokemon GO" on cognitive performance (memory, selective attention, concentration, mathematical calculation, linguistic reasoning) and on emotional intelligence (well-being, self-control, emotionality, sociability). The game relates to the search for creatures (pokemon) but not in a virtual place. The game in question is based on the search in real spaces since the creatures appear in the cellphones in certain spots. Results showed that the contact with the augmented reality game allowed adolescents to show their emotions to a decent degree and to have self-control at the same time. Their satisfaction from the game was evident in their facial expressions since they had the opportunity to depict meaningfully their emotions and to cultivate their emotional intelligence to the largest degree possible [34]. Specifically, adolescents showed a higher level in selective attention, concentration, and sociability which contributed to the cognitive and emotional cultivation of them.

The "Empowered Brain" is another social communication system that aims to improve children's and adults' social-emotional and cognitive skills. In the research 18 people (children and adults with ASD) took part and they were called to sit in pairs face-to-face and to wear special glasses designed with apps (Face2Face, Emotion Charades, Transition Master) to offer possibilities of the augmented reality. The results of the research showed that people with autism spectrum disorders had through those digital media the opportunity to express to a greater degree their emotions, recognize facial emotions, improve their social communication and to cultivate, of course, their emotional intelligence. It is a clinical study that is founded upon tangible data and allows important information regarding the emotions that occurred and the effect of technology [35]. Another research using the specific technology led to the same results [36].

In 2018, another research was conducted that concerned a 13-year-old adolescent male student diagnosed with ASD who received 16 augmented smart glasses-aided intervention sessions for two weeks to encounter activities of augmented reality based on the "Empowered Brain Face2Face" module. In the end, the researchers concluded that those kinds of tools were remarkably interesting for the students due to their technological aspect. The experiment reached the conclusion that interaction with that kind of activities can offer a high degree of sociability and can cultivate to a great extent the social virtues of the people and, much more importantly, of the children of the specific age group. The children with autism can demonstrate their emotional maturity and their emotions and work to a high degree collectively [37].

In another study augmented reality was combined with a concept map to help three students-children suffering from autistic disorders - of any kind and type - to further develop their social skills and promote even more their teamwork and their collectivity using concept visualization where social scenarios were shown in a tabletop role-play training platform. A concept map was created in that very context and it was based 
on the reduced ability of individuals with ASD to properly express social greetings. It helped children be taught and comprehend how they could become more social during the duration of the process of a new meeting to successfully realize the creation of a new contact [38]. The AR with the concept map added significantly to the increase of social reciprocity which grounded in empathy, awareness of emotional and interpersonal cues and appropriate responses.

During 2016, an article was published where augmented reality-based video modelling storybook (ARVMS) was used to improve the attention to nonverbal social cues and as a result to help participants better understand the facial expressions and emotions of the storybook characters to adopt it in daily life. In that article, the concept of augmented reality was studied, as well as the important role that the various activities play - the activities that are integrated in the former for the cultivation of emotions and of reactions of the participants ( 6 adolescents with autism) and that are depicted in their face and determined, by extension, their very behavior. At the same time, thanks to the emotional development that was achieved and to the further expansion of their social skills, the children were, that way, able to acquire a more active social activity and to be integrated in the community with the best way possible. In other words, through the applications of augmented reality, they will manage to cultivate a more active action and to amplify their emotionality and their sociability [39].

Another research came to the front during 2015 and moved towards the use and the study of the reactions of the children with autism when the latter meet an electronic GameBook founded upon augmented reality that presented the story of Tobias's adventure during a visit to a zoo park. The children that took part in the research had, that way, the opportunity to move to the recognition of emotions and to the expression of such senses so that they manage to amplify their social capabilities. The GameBook included a specific story-fairy tale with five scenarios and interactions and the hero managed in fact to showcase his emotional world and to help, as a result, the children in their journey of recognizing those emotional differences [40].

Additionally, in 2015, another team studied through technology the facial expressions and the emotions expressed by people when in contact with different situations and with augmented reality. A number of three adolescents was sufficient for the experiment. The augmented reality self-facial modelling (ARSFM) system provided 3-D facial expressions of six basic emotions (happiness, sadness, fear, disgust, surprise, anger) overlaid on participants' faces to help emotional recognition and emotional judgements. Those expressions were indicators of developing emotions, were noted down and were later studied by the scientists-researchers. At this point an important clarification must be highlighted: all participants suffered from autism and mental retardation. It was once more made clear that augmented reality helps to a great extent people with autism and much more adolescents to externalize their emotions and to be able to depict the latter and their thoughts without difficulties [10].

\section{Discussion}

The writing of the present article was surely a positive project which can give a new point of view in the research and which can offer a plethora of quite recent articles and studies. 
The articles referring to the theme of virtual and of augmented reality were surely quite helpful and they offered much information for the issue under scrutiny. They referred to all age groups, including children, adolescents, and adults, and it was made clear that in fact both types of technological reality affect everyone without exceptions. The scientists reached conclusions regarding the issue and presented important details for the research which were conducted and most of them were clinically and scientifically well-grounded.

Virtual and augmented reality are important aspects of technological development and progress and the possibilities they offer and will continue to offer in the future seem to be unlimited. Utilizing virtual and augmented reality as a technological tool can be done in many areas with positive and encouraging results [41-45]. They can enrich the 21 st-century skills, which are collaboration, communication, critical thinking, and problem solving [46] in the digital era in many domains such as education, work, leadership, and health.

In the present research, virtual and augmented reality applications provide an effective tool for enhancing emotional and social skills (Table 2). Emotional intelligence is a particularly important resource for people of all ages in the modern era and its cultivation - strengthening is considered necessary and indispensable $[47,48]$. The use of virtual and augmented reality and the integration of its elements in games, applications, programs with targeted actions can actively contribute to the development of emotional intelligence [49-51] in all age groups. They are attractive, useful, and promising tools that in combination with various strategies can cultivate emotional intelligence skills like emotion recognition, emotional expression, emotion regulation, empathy, emotional self/social awareness, in children and adults and in children and persons with special educational needs for a better self-development and for the improvement of their interpersonal relationships, daily interactions, problem-solving and decision making.

People with high levels of emotional intelligence have self-knowledge, self/social management and can show empathy. They in turn can help and motivate other people to come into meaningful contact with their emotions and themselves and increase their emotional competence. Emotional intelligence is closely related with the concepts of stability, harmony, love, and spirituality [52].

An issue in the present study that must be taken under consideration is the fact that some studies had a limited number of participants. That element could work in an inhibitory way for the extraction of conclusions since there were not a lot of participants to indicate that the results are more meaningful and certain. However, even in those cases, the samples managed to lead to important results and to clear and well-rounded points of view.

Finally, an element that is missing and that would perhaps be more beneficial to refer to future research is the significance that virtual and augmented reality have generally in the individuals' life outside the experiment. The studies focused on the way that the data and the percentages were formed at a specific time during which the experiment was conducted. That does not allow a deeper knowledge for the more general importance of said digital tools outside that temporal context. Therefore, it would be crucial that the research turns partially to that question as well, to study that aspect for a better understanding. Besides, without that aspect, it is not possible to have a well-rounded study and to depict whole conclusions that will, in the end, trigger a more intense review and contact with the issue under scrutiny. 
The findings of the present study will encourage new research projects on how to use VR/AR technology to increase in children and adults with or without special educational needs the recognition of verbal and non-verbal emotional cues, the comprehension of emotions, the management of them, the enhancement of emotional competence and social skills in emotional and social situations. It would be positive to create opportunities for the cultivation of emotional skills through the instillation of VR/AR technology into current practices and programs related to the educational environment, learning context, special education, working environment with employees, leadership, health, and other areas as the emotional element is evident everywhere. Creating intelligent virtual and augmented multiplayer reality environments would help the development of emotional and social skills. Educational approaches could be developed to cultivate empathy and raise awareness on a variety of everyday issues. Virtual and augmented reality games could also enhance emotional intelligence and socialization in children and people with disabilities in these two areas.

\section{Conslusions}

The findings from this study provide clear support in improving emotional skills. This demonstrates that virtual and augmented reality are promising mediums in promoting emotional and social capabilities in children, adolescents, and adults. Different forms of virtual and augmented reality environment should be considered to maximize results. Additional research with larger and diverse groups is needed to better examine the effectiveness of AR/VR technology in the field of emotional intelligence.

Therefore, emotional intelligence is a matter that has assumed to a great extent a central role in the research, and it has offered an important percentage of knowledge and of information to a more general scientific context. The research has progressed to a great degree and it has managed to use in the appropriate way the technology and the various digital methods in such a way that there is help provided both to the scientists and to the people themselves since the latter manage in fact to develop the kind of skills that are in the domain of emotional intelligence (emotion recognition, emotional expression, self-control, empathy).

Certainly, the methods and the tools that were used for the development of those activities have as a basis the improvement of the emotional intelligence and the enhancement of sociability of each member. In other words, virtual reality as well as augmented reality try to give a boost to the emotional intelligence of the people who took part in the studies. A great degree of interest can be found in the equivalent cultivation regarding the people who suffer from mental retardation and, more specifically, from autism.

The emotion can be cultivated by games, as well as other types of activities and exercises, that can include elements of those two categories of technology that are in every aspect differentiated. Therefore, a future goal may be to study methods that can best contribute to the development and improvement of emotional intelligence through virtual and augmented reality and to systematically analyze the perspectives that may be born in a more general context. 


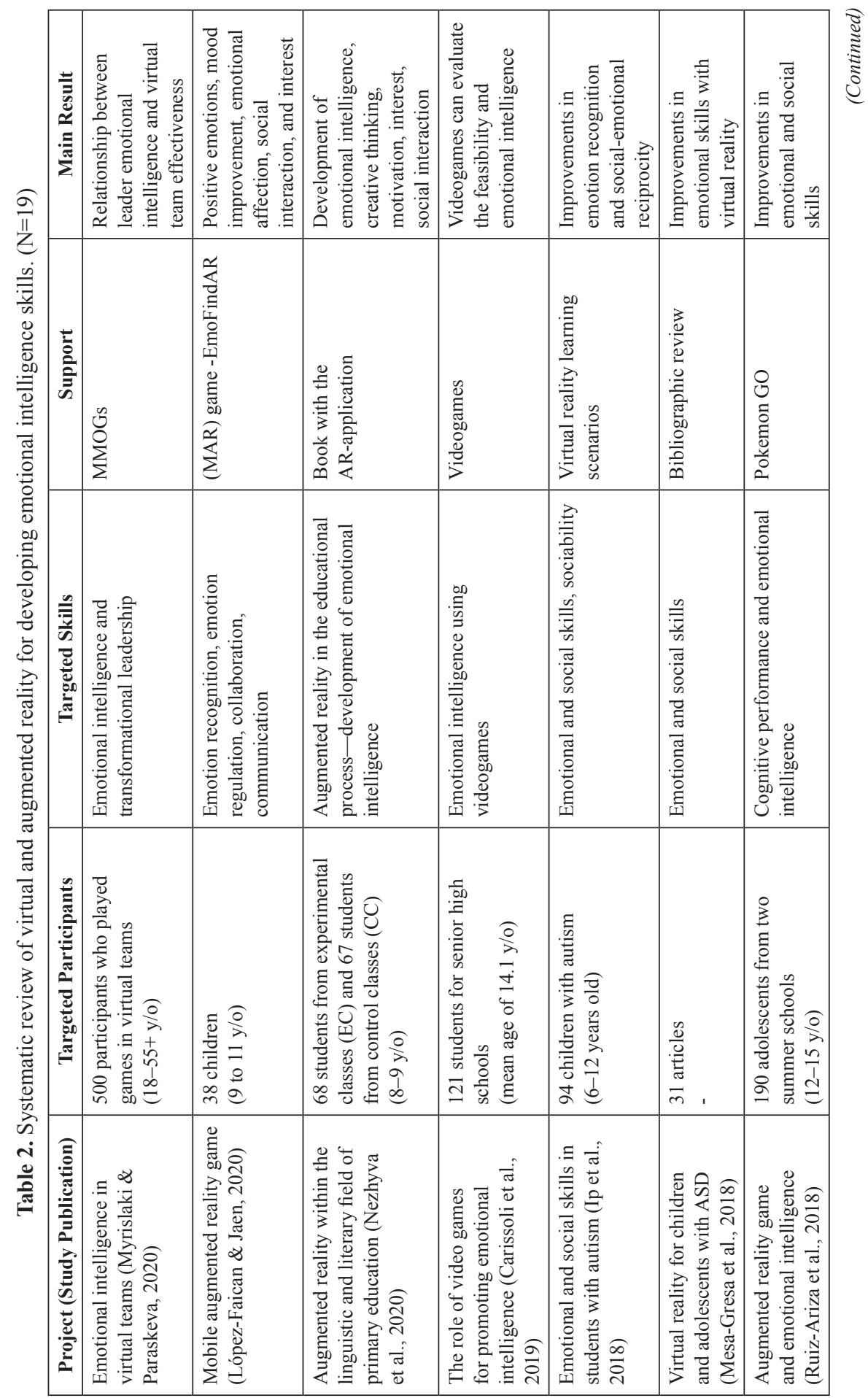




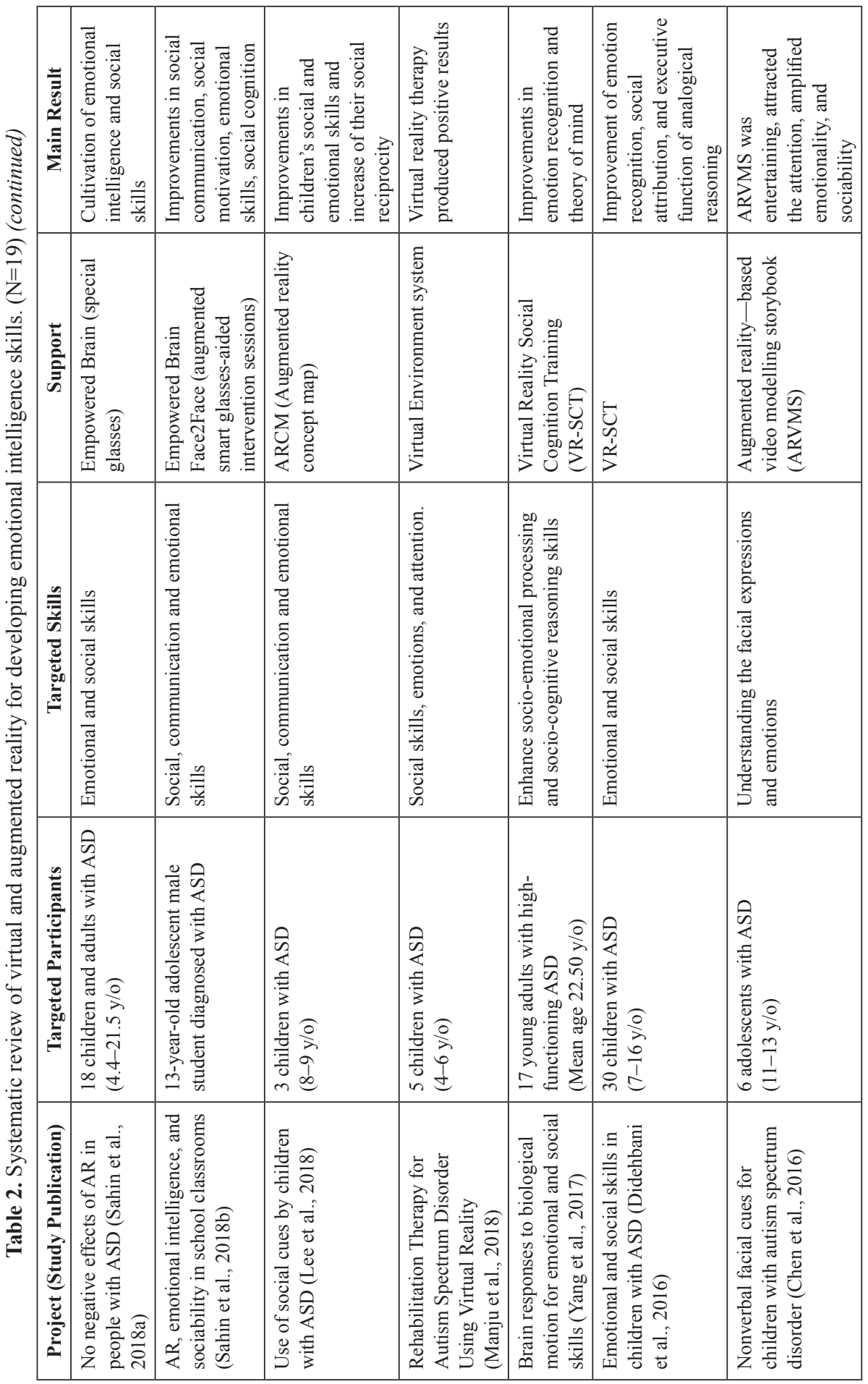




\begin{tabular}{|c|c|c|c|c|}
\hline 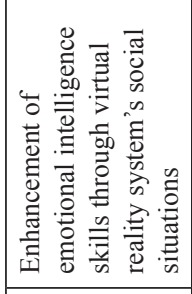 & 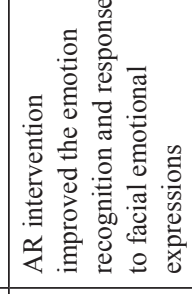 & 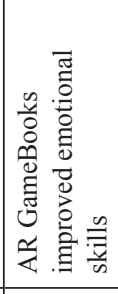 & 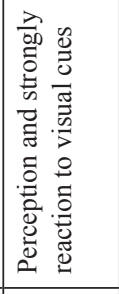 & 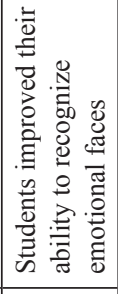 \\
\hline 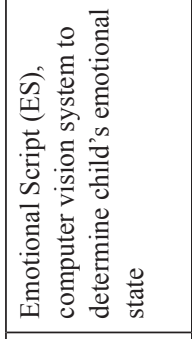 & 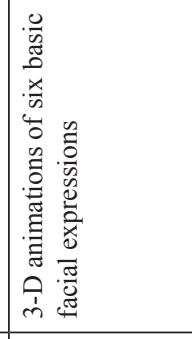 & 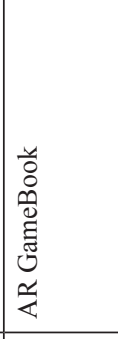 & 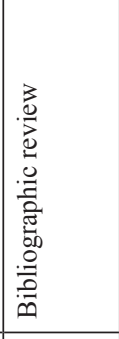 & 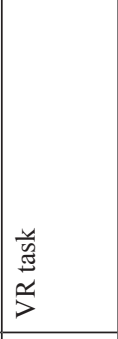 \\
\hline 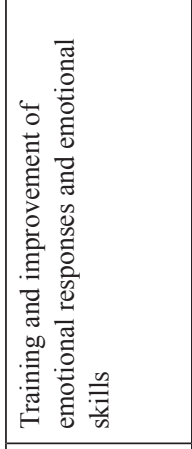 & 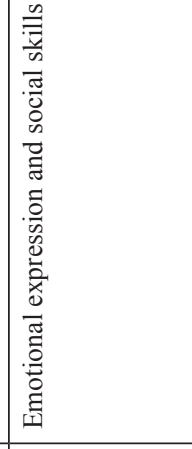 & 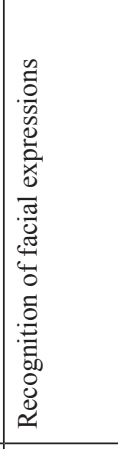 & 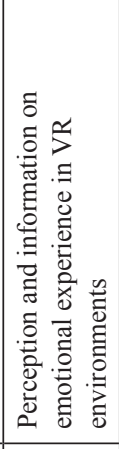 & 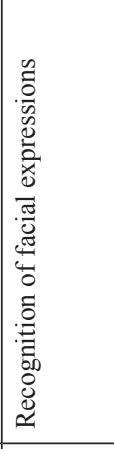 \\
\hline 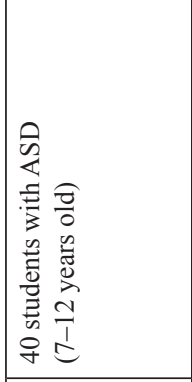 & 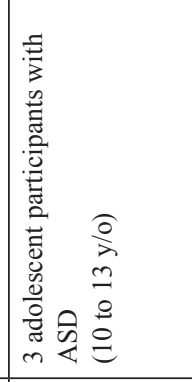 & 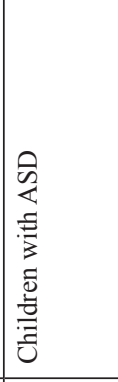 & 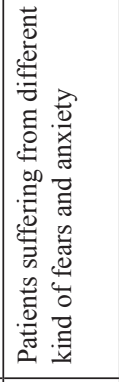 & 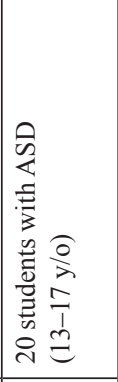 \\
\hline 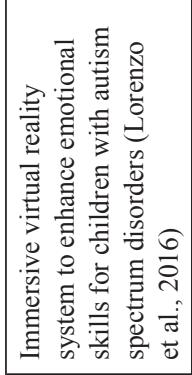 & 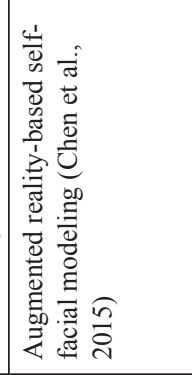 & 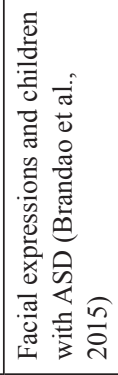 & 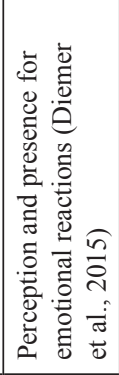 & 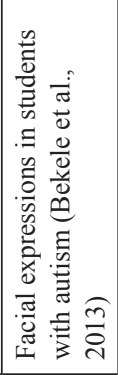 \\
\hline
\end{tabular}




\section{References}

[1] Drigas, A. S., \& Papoutsi, C. (2018). A new layered model on emotional intelligence. Behavioral Sciences, 8(5), 45. https://doi.org/10.3390/bs8050045

[2] Kotsou, I., Mikolajczak, M., Heeren, A., Grégoire, J., \& Leys, C. (2019). Improving emotional intelligence: A systematic review of existing work and future challenges. Emotion Review, 11(2), 151-165. https://doi.org/10.1177/1754073917735902

[3] D'Amico, A. (2018). The Use of Technology in the Promotion of Children's Emotional Intelligence: The Multimedia Program "Developing Emotional Intelligence". International Journal of Emotional Education, 10(1), 47-67.

[4] Hassan, A., Pinkwart, N., \& Shafi, M. (2021). Serious games to improve social and emotional intelligence in children with autism. Entertainment Computing, 100417. https:// doi.org/10.1016/j.entcom.2021.100417

[5] Papoutsi, C., Drigas, A., \& Skianis, C. (2018). Mobile Applications to Improve Emotional Intelligence in Autism-A Review. International Journal of Interactive Mobile Technologies, 12(6). https://doi.org/10.3991/ijim.v12i6.9073

[6] Murwonugroho, W., \& Ardianto, D. T. (2019). Visual Fantasy In Children's Learning Through Virtual \& Augmented Reality. Int. J. Sci. Technol. Res, 8, 2789-1795.

[7] Parekh, P., Patel, S., Patel, N., \& Shah, M. (2020). Systematic review and meta-analysis of augmented reality in medicine, retail, and games. Visual computing for industry, biomedicine, and art, 3(1), 1-20. https://doi.org/10.1186/s42492-020-00057-7

[8] Von Itzstein, G. S., Billinghurst, M., Smith, R. T., \& Thomas, B. H. (2019). Augmented Reality Entertainment: Taking Gaming Out of the Box.

[9] Bekele, M. K., Pierdicca, R., Frontoni, E., Malinverni, E. S., \& Gain, J. (2018). A survey of augmented, virtual, and mixed reality for cultural heritage. Journal on Computing and Cultural Heritage (JOCCH), 11(2), 1-36. https://doi.org/10.1145/3145534

[10] Chen, C. H., Lee, I. J., \& Lin, L. Y. (2015). Augmented reality-based self-facial modeling to promote the emotional expression and social skills of adolescents with autism spectrum disorders. Research in developmental disabilities, 36, 396-403. https://doi.org/10.1016/j. ridd.2014.10.015

[11] Diemer, J., Alpers, G. W., Peperkorn, H. M., Shiban, Y., \& Mühlberger, A. (2015). The impact of perception and presence on emotional reactions: a review of research in virtual reality. Frontiers in psychology, 6, 26. https://doi.org/10.3389/fpsyg.2015.00026

[12] Bonetti, F., Warnaby, G., \& Quinn, L. (2018). Augmented reality and virtual reality in physical and online retailing: A review, synthesis, and research agenda. Augmented reality and virtual reality, 119-132. https://doi.org/10.1007/978-3-319-64027-3_9

[13] Amin, D., \& Govilkar, S. (2015). Comparative study of augmented reality SDKs. International Journal on Computational Science \& Applications, 5(1), 11-26. https://doi. org/10.5121/ijcsa.2015.5102; https://doi.org/10.5120/20435-2768

[14] Billinghurst, M. (2014, February). Using augmented reality to create empathic experiences. In Proceedings of the 19th international conference on Intelligent User Interfaces (pp. 5-6). https://doi.org/10.1145/2557500.2568057

[15] Sidiq, M., Lanker, T., \& Makhdoomi, K. (2017). Augmented Reality vs Virtual Reality. International Journal of Computer Science and Mobile Computing, 6(6), 324-327.

[16] Cipresso, P., Giglioli, I. A. C., Raya, M. A., \& Riva, G. (2018). The past, present, and future of virtual and augmented reality research: a network and cluster analysis of the literature. Frontiers in psychology, 9, 2086. https://doi.org/10.3389/fpsyg.2018.02086 
[17] Boardman, R., Henninger, C. E., \& Zhu, A. (2020). Augmented reality and virtual reality: new drivers for fashion retail?. In Technology-Driven Sustainability (pp. 155-172). Palgrave Macmillan, Cham. https://doi.org/10.1007/978-3-030-15483-7 9

[18] Yusoff, A. (2010). A conceptual framework for serious games and its validation (Doctoral dissertation, University of Southampton). https://doi.org/10.1109/ICALT.2009.19

[19] Mysirlaki, S., \& Paraskeva, F. (2020). Emotional intelligence and transformational leadership in virtual teams: Lessons from MMOGs. Leadership \& Organization Development Journal. https://doi.org/10.1108/LODJ-01-2019-0035

[20] Drigas, A., \& Papoutsi, C. (2019). Emotional Intelligence as an Important Asset for HR in Organizations: Leaders and Employees. International Journal of Advanced Corporate Learning, 12(1). https://doi.org/10.3991/ijac.v12i1.9637

[21] Papoutsi, C., Drigas, A., \& Skianis, C. (2019). Emotional intelligence as an important asset for HR in organizations: Attitudes and working variables. International Journal of Advanced Corporate Learning, 12(2), 21. https://doi.org/10.3991/ijac.v12i2.9620

[22] Carissoli, C., \& Villani, D. (2019). Can videogames be used to promote emotional intelligence in teenagers? Results from EmotivaMente, a school program. Games for health journal, 8(6), 407-413. https://doi.org/10.1089/g4h.2018.0148

[23] Ip, H. H., Wong, S. W., Chan, D. F., Byrne, J., Li, C., Yuan, V. S., ... \& Wong, J. Y. (2018). Enhance emotional and social adaptation skills for children with autism spectrum disorder: A virtual reality enabled approach. Computers \& Education, 117, 1-15. https://doi. org/10.1016/j.compedu.2017.09.010

[24] Mesa-Gresa, P., Gil-Gómez, H., Lozano-Quilis, J. A., \& Gil-Gómez, J. A. (2018). Effectiveness of virtual reality for children and adolescents with autism spectrum disorder: an evidence-based systematic review. Sensors, 18(8), 2486. https://doi.org/10.3390/s18082486

[25] Manju, T., Padmavathi, S., \& Tamilselvi, D. (2017, December). A rehabilitation therapy for autism spectrum disorder using virtual reality. In international conference on intelligent information technologies (pp. 328-336). Springer, Singapore. https://doi. org/10.1007/978-981-10-7635-0 26

[26] Yang, Y. D., Allen, T., Abdullahi, S. M., Pelphrey, K. A., Volkmar, F. R., \& Chapman, S. B. (2017). Brain responses to biological motion predict treatment outcome in young adults with autism receiving virtual reality social cognition training: preliminary findings. Behaviour research and therapy, 93, 55-66. https://doi.org/10.1016/j.brat.2017.03.014

[27] Didehbani, N., Allen, T., Kandalaft, M., Krawczyk, D., \& Chapman, S. (2016). Virtual reality social cognition training for children with high functioning autism. Computers in human behavior, 62, 703-711. https://doi.org/10.1016/j.chb.2016.04.033

[28] Lorenzo, G., Lledó, A., Pomares, J., \& Roig, R. (2016). Design and application of an immersive virtual reality system to enhance emotional skills for children with autism spectrum disorders. Computers \& Education, 98, 192-205. https://doi.org/10.1016/j. compedu.2016.03.018

[29] Bekele, E., Zheng, Z., Swanson, A., Crittendon, J., Warren, Z., \& Sarkar, N. (2013). Understanding how adolescents with autism respond to facial expressions in virtual reality environments. IEEE transactions on visualization and computer graphics, 19(4), 711-720. https://doi.org/10.1109/TVCG.2013.42

[30] Bekele, E., Wade, J., Bian, D., Fan, J., Swanson, A., Warren, Z., \& Sarkar, N. (2016). Multimodal adaptive social interaction in virtual environment (MASI-VR) for children with Autism spectrum disorders (ASD). In 2016 IEEE Virtual Reality (VR) (pp. 121-130). IEEE. https://doi.org/10.1109/VR.2016.7504695 
[31] Oden, K. B., Lohani, M., McCoy, M., Crutchfield, J., \& Rivers, S. (2015). Embedding emotional intelligence into military training contexts. Procedia Manufacturing, 3, 4052-4059. https://doi.org/10.1016/j.promfg.2015.07.976

[32] Nezhyva, L. L., Palamar, S. P., \& Lytvyn, O. S. (2020). Perspectives on the use of augmented reality within the linguistic and literary field of primary education.

[33] López-Faican, L., \& Jaen, J. (2020). Emofindar: Evaluation of a mobile multiplayer augmented reality game for primary school children. Computers \& Education, 149, 103814. https://doi.org/10.1016/j.compedu.2020.103814

[34] Ruiz-Ariza, A., Casuso, R. A., Suarez-Manzano, S., \& Martínez-López, E. J. (2018). Effect of augmented reality game Pokémon GO on cognitive performance and emotional intelligence in adolescent young. Computers \& Education, 116, 49-63. https://doi.org/10.1016/j. compedu.2017.09.002

[35] Sahin, N. T., Keshav, N. U., Salisbury, J. P., \& Vahabzadeh, A. (2018). Safety and lack of negative effects of wearable augmented-reality social communication aid for children and adults with autism. Journal of clinical medicine, 7(8), 188. https://doi.org/10.3390/ jem7080188

[36] Vahabzadeh, A., Keshav, N. U., Abdus-Sabur, R., Huey, K., Liu, R., \& Sahin, N. T. (2018). Improved socio-emotional and behavioral functioning in students with autism following school-based smartglasses intervention: Multi-stage feasibility and controlled efficacy study. Behavioral Sciences, 8(10), 85. https://doi.org/10.3390/bs8100085

[37] Sahin, N. T., Abdus-Sabur, R., Keshav, N. U., Liu, R., Salisbury, J. P., \& Vahabzadeh, A. (2018, September). Case Study of a Digital Augmented Reality Intervention for Autism in School Classrooms: Associated With Improved Social Communication, Cognition, and Motivation via Educator and Parent Assessment. In Frontiers in Education (Vol. 3, p. 57). Frontiers. https://doi.org/10.3389/feduc.2018.00057

[38] Lee, I. J., Chen, C. H., Wang, C. P., \& Chung, C. H. (2018). Augmented reality plus concept map technique to teach children with ASD to use social cues when meeting and greeting. The Asia-Pacific Education Researcher, 27(3), 227-243. https://doi.org/10.1007/ s40299-018-0382-5

[39] Chen, C. H., Lee, I. J., \& Lin, L. Y. (2016). Augmented reality-based video-modeling storybook of nonverbal facial cues for children with autism spectrum disorder to improve their perceptions and judgments of facial expressions and emotions. Computers in Human Behavior, 55, 477-485. https://doi.org/10.1016/j.chb.2015.09.033

[40] Brandão, J., Cunha, P., Vasconcelos, J., Carvalho, V., \& Soares, F. (2015). An augmented reality gamebook for children with autism spectrum disorders. In the International Conference on E-Learning in the Workplace 2015 (pp. 1-6).

[41] Diegmann, P., Schmidt-Kraepelin, M., Eynden, S., \& Basten, D. (2015). Benefits of augmented reality in educational environments-a systematic literature review. Benefits, 3(6), $1542-1556$.

[42] Loureiro, S. M. C., Guerreiro, J., \& Ali, F. (2020). 20 years of research on virtual reality and augmented reality in tourism context: A text-mining approach. Tourism Management, 77, 104028. https://doi.org/10.1016/j.tourman.2019.104028

[43] Moro, C., SStromberga, Z., Raikos, A., \& Stirling, A. (2017). The effectiveness of virtual and augmented reality in health sciences and medical anatomy. Anatomical sciences education, 10(6), 549-559. https://doi.org/10.1002/ase.1696

[44] Papanastasiou, G., Drigas, A., Skianis, C., Lytras, M., \& Papanastasiou, E. (2019). Virtual and augmented reality effects on K-12, higher and tertiary education students' twenty-first century skills. Virtual Reality, 23(4), 425-436. https://doi.org/10.1007/s10055-018-0363-2 
[45] Ventura, S., Baños, R. M., Botella, C., \& Mohamudally, N. (2018). Virtual and augmented reality: New frontiers for clinical psychology. State of the Art Virtual Reality and Augmented Reality Knowhow, 99-118. https://doi.org/10.5772/intechopen.74344

[46] Rafiq, K. R. M., \& Hashim, H. (2018). Augmented Reality Game (ARG), 21st century skills and ESL classroom. Journal of Educational and Learning Studies, 1(1), 29-34. https://doi. org $/ 10.32698 / 0232$

[47] Patti, J., Holzer, A. A., Brackett, M. A., \& Stern, R. (2015). Twenty-first-century professional development for educators: a coaching approach grounded in emotional intelligence. Coaching: An International Journal of Theory, Research and Practice, 8(2), 96-119. https:// doi.org/10.1080/17521882.2015.1061031

[48] Wheeler, R. (2016). Soft skills-the importance of cultivating emotional intelligence. AALL Spectrum, 20(3), 28.

[49] Billinghurst, M., Clark, A., \& Lee, G. (2015). A survey of augmented reality. https://doi. org/10.1561/9781601989215

[50] Huang, T. C., Chen, C. C., \& Chou, Y. W. (2016). Animating eco-education: To see, feel, and discover in an augmented reality-based experiential learning environment. Computers \& Education, 96, 72-82. https://doi.org/10.1016/j.compedu.2016.02.008

[51] Martínez, A. A., Benito, J. R. L., González, E. A., \& Ajuria, E. B. (2017, November). An experience of the application of Augmented Reality to learn English in Infant Education. In 2017 international symposium on computers in education (siie) (pp. 1-6). IEEE. https://doi. org/10.1109/SIIE.2017.8259645

[52] Serrat, O. (2017). Understanding and developing emotional intelligence. In Knowledge solutions (pp. 329-339). Springer, Singapore. https://doi.org/10.1007/978-981-10-0983-9 37

\section{$7 \quad$ Authors}

Chara Papoutsi is a PhD Candidate in Information and Communication Systems Engineering at the University of the Aegean in Samos, Greece. She holds a Master's degree in Applied Pedagogy at the National and Kapodistrian University of Athens. She is a teacher in a primary school. She has publications on empathy and emotionalintelligence and she is also with NCSR DEMOKRITOS, Institute of Informatics and Telecommunications, Net Media Lab, Athens, Greece, papoutsi.xara@yahoo.com

Athanasios Drigas is a Research Director at N.C.S.R. "Demokritos", IIT-Net Media Lab \& Mind- Brain R\&D, Agia Paraskevi, 153 10, Athens, Greece (e-mail: dr@, iit.demokritos.gr).

Charalabos Skianis is a professor and a Vice Rector at the University of the Aegean (Department of Information and Communication Systems) in Samos, Greece (e-mail: cskianis@aegean.gr)

Article submitted 2021-05-13. Resubmitted 2021-07-02. Final acceptance 2021-07-15. Final version published as submitted by the authors. 